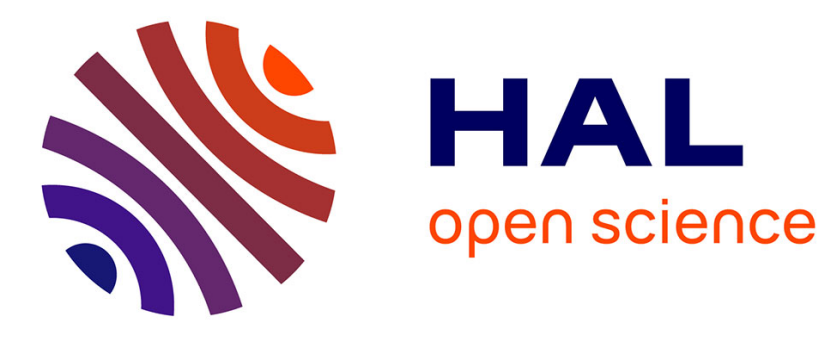

\title{
Evaluation of a new point-of-care testing for creatinine and urea measurement
}

\author{
Anne-Sophie Bargnoux, Nils Kuster, Thibault Sutra, Laëtitia Laroche, Annie
}

Rodriguez, Marion Morena, Leila Chenine, Lotfi Chalabi, Anne-Marie Dupuy, Stéphanie Badiou, et al.

\section{To cite this version:}

Anne-Sophie Bargnoux, Nils Kuster, Thibault Sutra, Laëtitia Laroche, Annie Rodriguez, et al.. Evaluation of a new point-of-care testing for creatinine and urea measurement. Scandinavian Journal of Clinical and Laboratory Investigation, In press, 81 (4), pp.280-297. 10.1080/00365513.2021.1914344 . hal-03211936

\section{HAL Id: hal-03211936 https://hal.science/hal-03211936}

Submitted on 29 Apr 2021

HAL is a multi-disciplinary open access archive for the deposit and dissemination of scientific research documents, whether they are published or not. The documents may come from teaching and research institutions in France or abroad, or from public or private research centers.
L'archive ouverte pluridisciplinaire HAL, est destinée au dépôt et à la diffusion de documents scientifiques de niveau recherche, publiés ou non, émanant des établissements d'enseignement et de recherche français ou étrangers, des laboratoires publics ou privés. 


\title{
Evaluation of a new point-of-care testing for creatinine and urea measurement
}

\author{
Anne-Sophie Bargnoux ${ }^{a}$, Nils Kuster ${ }^{a}$, Thibault Sutra ${ }^{a}$, Laëtitia Laroche ${ }^{b}$, Annie Rodriguez ${ }^{b}$, Marion Morena ${ }^{a}$, \\ Leila Chenine $^{c}$, Lotfi Chalabi ${ }^{d}$, Anne-Marie Dupuy ${ }^{b}$, Stéphanie Badiou ${ }^{a}$ and Jean-Paul Cristol ${ }^{a}$ \\ aDépartement de Biochimie et Hormonologie, PhyMedExp, INSERM, CNRS, CHU de Montpellier, Université de Montpellier, Montpellier, \\ France; 'bépartement de Biochimie et Hormonologie, CHU de Montpellier, Université de Montpellier, Montpellier, France; 'Département de \\ Néphrologie, Dialyse et Transplantation, CHU de Montpellier, Université de Montpellier, Montpellier, France; ${ }^{\mathrm{d}}$ AIDER, Montpellier, France
}

\begin{abstract}
Point of care testing makes it possible to obtain results in an extremely short time. Recently, radiometer has expanded the panel of tests available on its ABL90 FLEX PLUS blood gas analyzer (ABL90) by adding urea and creatinine. The aim of this study was to verify the performance of these new parameters. This included assessment of imprecision, linearity, accuracy by comparison with central laboratory standard assays and interferences. In addition, clinical utility in a dialysis center was evaluated. Withinlab coefficients of variation were close to $2 \%$. The mean and limits of agreement (mean \pm 1.96 SD) of the difference between ABL90 and Roche enzymatic assays on cobas 8000 were 0.5 (from -1.4 to 2.3) $\mathrm{mmol} / \mathrm{L}$ and -0.9 (from -19.5 to 17.8$) \mu \mathrm{mol} / \mathrm{L}$ for urea and creatinine, respectively. The ABL90 enzymatic urea and creatinine assays met the acceptance criteria based on biological variation for imprecision and showed good agreement with central laboratory. The two assays were unaffected by hematocrit variation between 20 and $70 \%$, hemolysis and icterus interferences. It should be noted that the relationship between lab methods and ABL90 was conserved even for high pre-dialysis values allowing easy access to dialysis adequacy parameters $(K t / V)$ and muscle mass evaluation (creatinine index). Rapid measurement of creatinine and urea using whole blood specimens on ABL90 appears as a fast and convenient method. Analytical performances were in accordance with our expectations without any significant interferences by hemolysis or icterus.
\end{abstract}

\section{Introduction}

Blood gas analyzers are routinely used as point of care testing (POCT) for rapid decision making in clinical departments with the advantages of low volume of whole blood and short delay of results in real time [1,2]. In the last few years, many parameters beyond blood gas analysis have been implemented including creatinine as a biomarker of renal function [3,4]. POCT for kidney function is an attractive method to make immediate decision in emergency unit, imaging department or ambulatory care [5-8]. However, discrepancies with the central laboratory have been reported and adoption in clinical practice has therefore been limited $[9,10]$. The ABL90 FLEX PLUS blood gas analyzer (ABL90) (Radiometer Medical ApS, Copenhagen, Denmark) is an easy-to-use, portable $(<12 \mathrm{~kg})$ and compact $(250 \times 290 \times 472 \mathrm{~mm})$ cartridge-type analyzer that measures blood gas, electrolytes, metabolites and co-oximetry in heparinized whole blood. Since then, CE-marked point-of-care tests for creatinine and urea have been added to the ABL90 blood gas analyzer's test menu.

The aim of this study was to verify the performance of the new parameters urea and creatinine on the ABL90. We assessed imprecision, linearity, comparison of the ABL90 to a laboratory standard and interferences. In addition, ABL90 was evaluated in a dialysis center with a specific interest to dialysis adequacy measurement.

\section{Materials and methods}

\section{Study design}

Analytical evaluation of urea and creatinine on the ABL90 was performed in the central laboratory. Whole blood heparinized samples were randomly selected from those routinely collected in our Biochemistry Department of Lapeyronie University Hospital, CHU Montpellier (Montpellier, France). When manipulation of samples was necessary, the sample was then mixed for a minimum of $5 \mathrm{~h}$ to establish equilibrium between red bloods cells and plasma [11]. This study was approved by the Institutional Review Board of the Montpellier University Hospital (number 2018_IRB_MTP_12-13).

\section{Methods}

Urea on the ABL90 is measured potentiometrically using an ammonium ion-selective electrode after hydrolyzation catalyzed by the urease enzyme [12]. Creatinine on the ABL90 
is determined by an isotope dilution mass spectrometry (IDMS)-traceable enzymatic method based on the amperometric measurement of oxygen $[3,13,14]$. During the study, one lot of sensor cassettes (no. 80) and two lots of pack solutions (BC01 and BD01) were used.

In the central laboratory, routine measurements of both parameters are performed on c701/cobas 8000 analyzer (Roche Diagnostics GmbH, Mannheim, Germany). The first steps of the reaction scheme on cobas 8000 involve the same enzymes, namely urease and creatininase/creatinase/ sarcosine oxidase for urea and creatinine determination, respectively. However, the detection principle of the final product is different. On cobas 8000 , the ammonium product is detected by spectrophotometry for urea and the detection of hydrogen peroxide produced is by colorimetry for creatinine.

In addition, an ultra-performance liquid chromatography tandem mass spectrometry (UPLC/MS/MS) method is used as a reference creatinine assay, according to manufacturer recommendations in order to analyze interferences. For sample preparation, plasma is treated with $0.5 \mathrm{mM}$ perfluoroheptanoic acid containing the internal standard (creatinine-N-methyl-d3). After protein precipitation, supernatant is injected for LC-MS/MS analysis (UPLC Acquity coupled to a XevoTQD, Waters Corporation, Milford, MA). Creatinine ionization is performed using positive electrospray ionization of $[\mathrm{M}+\mathrm{H}]^{+}$and the XevoTQD monitored the following transitions: $\mathrm{m} / \mathrm{z} 114$ to $\mathrm{m} / \mathrm{z} 44$ and $\mathrm{m} / \mathrm{z} 114$ to $\mathrm{m} / \mathrm{z} 86$ for creatinine quantification and qualification, respectively, and $\mathrm{m} / z 117$ to $\mathrm{m} / z 47$ for creatinine-N-methyl-d3.

\section{Imprecision and linearity}

Imprecision was assessed using the Clinical and Laboratory Standards Institute (CLSI) EP15-A3 protocol (one run per day, five replicates per run for five days, $n=25$ replicates per sample) [15] by repeat analysis of four levels of radiometer aqueous quality control samples (Qualicheck) and using patients duplicates $(n=55)$. Controls range from 5 to $40 \mathrm{mmol} / \mathrm{L}$ for urea and from 180 to $730 \mu \mathrm{mol} / \mathrm{L}$ for creatinine. Further dilutions of these quality controls were made to obtain lower ranges of values and run according to the same protocol. Linearity was evaluated following the CLSI EP6-A protocol [16] by successive dilutions of patient blood samples at a high creatinine/urea concentration $(20 \mathrm{mmol} / \mathrm{L}$ and $620 \mu \mathrm{mol} / \mathrm{L}$ for urea and creatinine, respectively) at the following theoretical concentrations of $100 \%, 90 \%, 80 \%$, $70 \%, 60 \%, 50 \%, 40 \%, 30 \%, 20 \%$, and $10 \%$ of the initial concentration and analyzed in duplicate.

\section{Comparison studies}

ABL90 results were compared with those obtained in the central laboratory using the Roche assays on c701/cobas 8000 analyzer. Excess whole blood samples were selected and assessed on both ABL90 and, after centrifugation, on cobas 8000 during a minimum of five days to include dayto-day variation. The Chronic Kidney Disease Epidemiology
Collaboration (CKD-EPI) formula was used to calculate the estimated glomerular filtration rate (eGFR) (or residual renal function) [17]. In addition, urea and creatinine were determined in pre- and post-dialysis samples of 51 hemodialysis (HD) patients ( 15 women, 36 men, median age was 74.4 years) during the mid-week session. Dialysis adequacy was estimated by calculation of Daugirdas single pool equation (sp $K t / V$ urea) as follows: sp $K t / V=-\mathrm{Ln}$ ([ureapost]/ [ureapre] $)-0.008 \times \mathrm{tHD}+((4-3.5 \times$ [ureapost] $/$ [ureapre]) - (BWpre - BWpost)/BWpost)) where sp is the single pool, pre and post correspond to the pre- and posttreatment conditions, respectively, tHD is the time on dialysis in hours, [urea] is the urea concentration in $\mathrm{mmol} / \mathrm{L}$ and BW is the body weight in $\mathrm{kg}$ [18]. Lean body mass was assessed using creatinine index [19] as follows: CI ( $\mathrm{mg} / \mathrm{kg} /$ day) $=16.21+1.12 \times[1$ if male; 0 if female $]-0.06 \times$ age (years) $-0.08 \times \mathrm{sp} \mathrm{Kt} / \mathrm{V}$ urea $+0.009 \times$ creatinine pre $\mathrm{HD}$ $(\mu \mathrm{mol} / \mathrm{L})$.

\section{Interferences}

Susceptibility of the measurement procedure was tested for hematocrit, hemolysis and icterus. The impact of hematocrit was performed using heparinized whole blood pools representing three different levels of analytes $(2.7,6$ and $14.6 \mathrm{mmol} / \mathrm{L}$ for urea; 59, 75 and $508 \mu \mathrm{mol} / \mathrm{L}$ for creatinine) and five different levels of hematocrit. Heparinized blood tubes were centrifuged to separate red blood cells and plasma. Red blood cells were then added back to plasma to obtain hematocrit values approximating 20\%, 40\%, 50\%, $60 \%$ and $70 \%$ [14]. Urea and creatinine concentrations were measured in the plasma and whole blood samples. For hemolysis testing, an hemolysate was prepared according to the protocol CLSI EP7-A2 using the osmotic shock procedure [20]. Heparinized whole blood pools representing two different levels of analytes ( 5 and $15.5 \mathrm{mmol} / \mathrm{L}$ for urea; 46 and $142 \mu \mathrm{mol} / \mathrm{L}$ for creatinine) were prepared and split in equal volumes. Increasing amounts of hemoglobin titrated hemolysate were added under a constant total volume into tubes of $1 \mathrm{~mL}$ with compensation by addition of $\mathrm{NaCl} 0.9 \%$ as previously described [21]. The hemolysis index was determined on c701/cobas 8000 analyzer after measurement on ABL90 and centrifugation. The percentage difference between the 'manipulated' sample $(M)$ and the control sample $(C)$ was calculated for each condition using the equation $[(M-C) / C] \times 100$.

The potential interference by bilirubin was evaluated using patient specimens according to CLSI EP07-A2 [20]. For this purpose, anonymized icteric whole blood samples were analyzed by two different methods (ABL90 and Roche Cobas 8000). The relationship between the two measurement procedures (systematic bias) was determined from analysis of control (non icteric) whole blood samples. The icterus index was determined on c701/cobas 8000 analyzer after measurement on ABL90 and centrifugation. To better characterize the bilirubin interference on creatinine measurement, samples were assessed by a UPLC/MS/MS method as a third measurement procedure. 
Table 1. Mean values, repeatability $\left(\mathrm{CV}_{\mathrm{R}}\right)$ and within-lab $\left(\mathrm{CV}_{\mathrm{WL}}\right)$ coefficient of variation for the four levels of radiometer aqueous quality control samples and the two diluted aqueous quality control samples.

\begin{tabular}{|c|c|c|}
\hline & Urea (mmol/L) & Creatinine $(\mu \mathrm{mol} / \mathrm{L})$ \\
\hline \multicolumn{3}{|c|}{ Control S7640, lot 3} \\
\hline Mean & 4.9 & 182 \\
\hline $\mathrm{CV}_{\mathrm{R}}, \%$ & 0.6 & 1.1 \\
\hline $\mathrm{CV}_{\mathrm{WL}}, \%$ & 1.4 & 1.9 \\
\hline \multicolumn{3}{|c|}{ Control S7630, lot 3} \\
\hline Mean & 14.4 & 416 \\
\hline $\mathrm{CV}_{\mathrm{R}}, \%$ & 0.6 & 1.3 \\
\hline$C V_{W L} \%$ & 0.8 & 1.3 \\
\hline \multicolumn{3}{|c|}{ Control S7650, lot 3} \\
\hline Mean & 30.5 & 573 \\
\hline $\mathrm{CV}_{\mathrm{R}}, \%$ & 0.7 & 0.7 \\
\hline $\mathrm{CV}_{\mathrm{WL}}, \%$ & 1.9 & 1.5 \\
\hline \multicolumn{3}{|c|}{ Control S7660, lot 4} \\
\hline Mean & 40.1 & 721 \\
\hline $\mathrm{CV}_{\mathrm{R}}, \%$ & 0.9 & 0.6 \\
\hline $\mathrm{CV}_{\mathrm{WL}}, \%$ & 1.7 & 1.9 \\
\hline \multicolumn{3}{|c|}{ Diluted control 1} \\
\hline Mean & 1.1 & 41 \\
\hline $\mathrm{CV}_{\mathrm{R}}, \%$ & 5.9 & 1.1 \\
\hline $\mathrm{CV}_{\mathrm{WL}}, \%$ & 6.2 & 1.5 \\
\hline \multicolumn{3}{|c|}{ Diluted control 2} \\
\hline Mean & 2.5 & 79 \\
\hline $\mathrm{CV}_{\mathrm{R}}, \%$ & 1.0 & 1.8 \\
\hline $\mathrm{CV}_{\mathrm{WL}}, \%$ & 1.1 & 2.1 \\
\hline
\end{tabular}

\section{Statistical analysis}

A one-way analysis of variance (ANOVA) was performed for each aqueous control concentration to estimate repeatability $\left(\% \mathrm{CV}_{\mathrm{R}}\right)$ and within-lab imprecision $\left(\% \mathrm{CV}_{\mathrm{WL}}\right)$ after carrying out Grubbs' test to detect potential outliers. Imprecision on whole blood samples was assessed by calculating standard deviation (SD) of the duplicates of each measurement (paired data) [13]. For linearity, comparison between expected and obtained values was made by linear regression analysis. The Passing-Bablok regression analysis was performed to compare data from the different methods. In addition, the scatter of differences was visualized according to the Bland-Altman representation. The agreement at the five CKD diagnostic thresholds was calculated with the Kappa statistics. Comparison of sp Kt/V and CI derived from ABL90 or Roche measurement was made by paired Student's $t$-test. To evaluate interferences from hematocrit or hemolysis, the percent change was compared to predetermined criteria which are the acceptable change limit (ACL) [22] and the reference change value (RCV) [23] using a 1.65 factor for the unidirectional (increase or decrease) probability of change fixed at $95 \%$. The ACL was calculated using the formula $\mathrm{ACL}=1.65 \times(2)^{1 / 2} \times \mathrm{CVa}$, where $\mathrm{CVa}$ is the analytical imprecision. The $\mathrm{CVa}$ was calculated from radiometer internal quality control embedded in the $\mathrm{ABL} 90$ solutions pack. The RCV was calculated using the formula based on both imprecision and biological variation RCV $=$ $1.65 \times(2)^{1 / 2} \times\left(\mathrm{CVa}^{2}+\mathrm{CVw}^{2}\right)^{1 / 2}$, where $\mathrm{CVw}$ is the median within-subject variation found in the European Federation of Clinical Chemistry and Laboratory Medicine (EFLM) Biological Variation Database [24,25]. The within-subject biological variation estimates $(\mathrm{CVw}[95 \% \mathrm{CI}])$ are 13.9 [9.5-14.4] \% and 4.5 [4.3-5.7] \% for urea and creatinine, respectively [24]. Results of bilirubin interference were interpreted by plotting bias versus potential interferent using linear regression analysis. Comparison of the bias between control and test group was performed by the Mann-Whitney test. Statistical analysis was carried out with the XLSTAT ${ }^{\circledR}$ software for Windows, version 2016.06.35661 (New York, NY) and the statistical significance was set at $p<.05$.

\section{Results}

\section{Imprecision and linearity}

Repeatability and within-laboratory CVs were below $2 \%$, except for urea in the diluted control at the value of $1.1 \mathrm{mmol} / \mathrm{L}$ (Table 1). Whole blood imprecision results $(n=55)$ showed paired $\mathrm{SD}$ of $0.2 \mathrm{mmol} / \mathrm{L}$ (result range $2.7-37.6 \mathrm{mmol} / \mathrm{L}$ ) for urea and $4 \mu \mathrm{mol} / \mathrm{L}$ (result range 12-1039) for creatinine. Regression equations for linearity on the ABL90 were $y=1.000 x-1.35, r^{2}=0.982$ and $y=0.997 x-14.5, r^{2}=0.997$, for urea and creatinine, respectively. Recoveries for the different dilutions ranged from $73 \%$ to $93 \%$ and $91 \%$ to $98 \%$, for urea and creatinine, respectively.

\section{Comparison studies}

For the comparison study, we analyzed excess whole blood from 102 patients (median age 67 years; 41 women and 61 men) that were selected to cover the analytical range of $2-40 \mathrm{mmol} / \mathrm{L}$ for urea (Figure 1) and $10-1000 \mu \mathrm{mol} / \mathrm{L}$ for creatinine (Figure 2). The mean and limits of agreement (mean $\pm 1.96 \mathrm{SD}$ ) of the difference according to Bland-Altman's study between ABL90 and Roche were 0.5 (from -1.4 to 2.3 ) $\mathrm{mmol} / \mathrm{L}$ for urea and -0.9 (from -19.5 to 17.8$) \mu \mathrm{mol} / \mathrm{L}$ for creatinine. The mean and limits of agreement of the bias between eGFR (or residual function) based on ABL90 and Roche creatinine were 1.2 (from -5.3 to 7.7$) \mathrm{mL} / \mathrm{min} / 1.73 \mathrm{~m}^{2}$. The agreement at the five CKD diagnostic thresholds was 99\% (kappa statistics, 0.96; 95\% CI, 0.96-1.00). In pre-dialysis patients $(n=51)$ with high urea and creatinine levels, the following Passing-Bablok's regression equations were obtained: ABL90 urea $=0.97$ Cobas urea +0.48 and ABL90 creatinine $=1.02$ Cobas creatinine - 16.41. Median urea single-pool $\mathrm{Kt} / \mathrm{V}$ was 1.76 for both Cobas [interquartile range, IQR 1.57-2.01] and ABL [IQR 1.44-2.05] assays. Median creatinine index was comparable between Cobas (17.5 [IQR 16.5-19.3] mg/kg/j) and ABL (17.6 [IQR 16.4-19.4] mg/kg/j) (Figure 3).

\section{Interferences}

The ACL cut-offs were $5.8 \%$ for both urea and creatinine. The RCV cut-offs were 33 and $12 \%$ for urea and creatinine, respectively. Considering hematocrit interference, differences never exceeded $6 \%$ for values between 20 and $70 \%$ at the three tested levels for both urea and creatinine. The difference was $-17 \%$ between plasma and whole blood at urea level of 2.7 and $6 \mathrm{mmol} / \mathrm{L}$. The variation was negligible $(0.3 \%)$ at the urea level of $14.3 \mathrm{mmol} / \mathrm{L}$. The difference was 


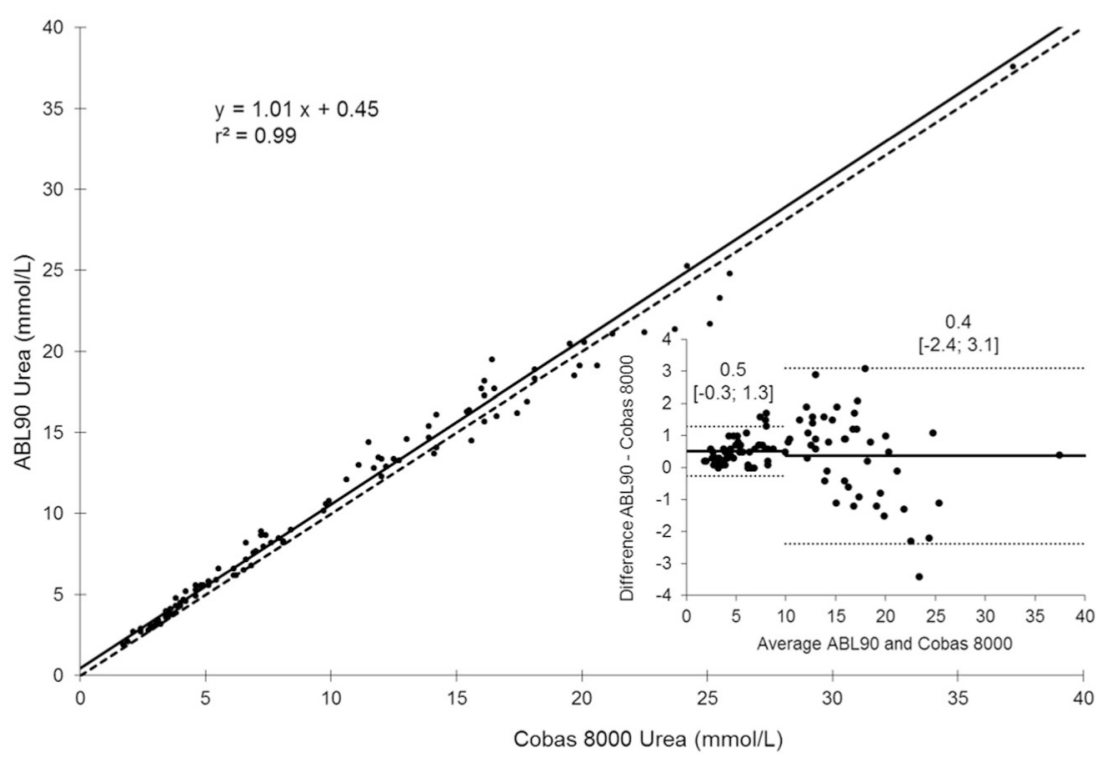

Figure 1. The Passing-Bablok regression $(n=102)$ of enzymatic urea on $c 701 /$ Cobas 8000 (plasma) and ABL 90 Flex Plus analyzers, and the Bland-Altman plot of differences against means for patient samples with both analyzers. For the Bland-Altman representation, the mean (solid horizontal line) and limits of agreement (dashed lines) of the bias ( $\mathrm{mmol} / \mathrm{L})$ were computed for patients with urea concentration $<10 \mathrm{mmol} / \mathrm{L}(n=58)$.

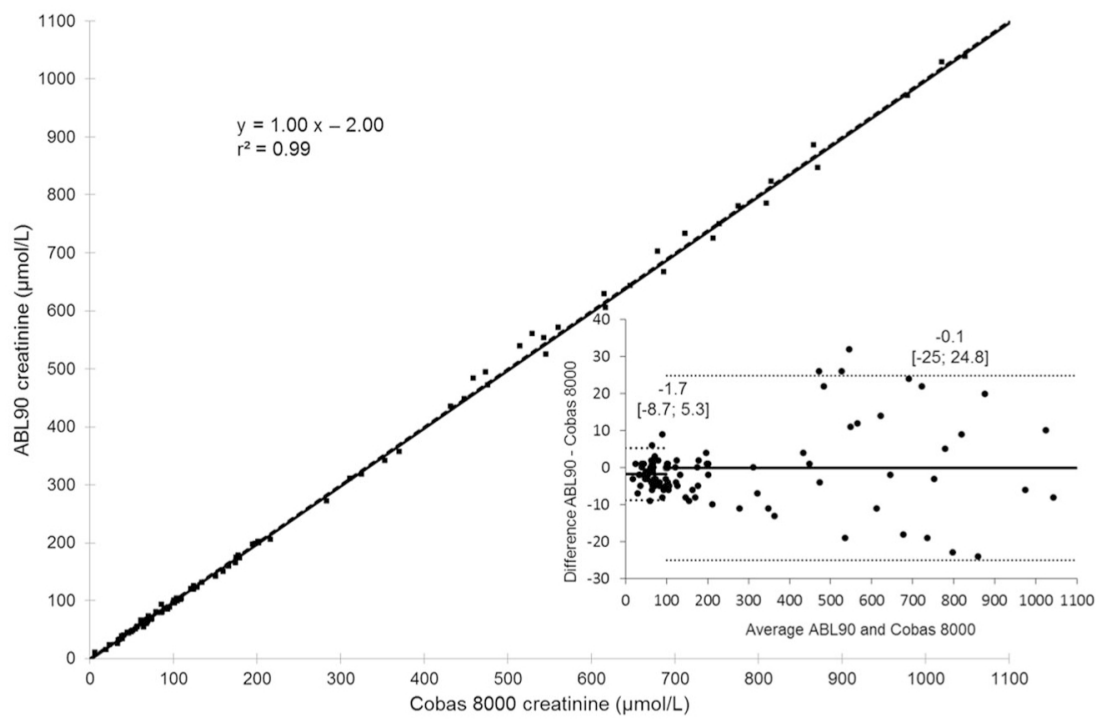

Figure 2. The Passing-Bablok regression $(n=102)$ of enzymatic creatinine on $c 701 /$ Cobas 8000 (plasma) and ABL 90 Flex Plus analyzers, and the Bland-Altman plot of differences against means for patient samples with both analyzers. For the Bland-Altman representation, the mean (solid horizontal line) and limits of agreement (dashed lines) of the bias $(\mu \mathrm{mol} / \mathrm{L})$ were computed for patients with creatinine concentration $<100 \mu \mathrm{mol} / \mathrm{L}, n=48)$ and $>100 \mu \mathrm{mol} / \mathrm{L}(n=54)$.

$-9.3 \%$ between plasma and whole blood at creatinine level of $59 \mu \mathrm{mol} / \mathrm{L}$. The variation was negligible at creatinine concentrations of 75 and $508 \mu \mathrm{mol} / \mathrm{L}(-4.9$ and $-3.5 \%$, respectively). Hemolysis led to a positive bias for urea which exceeded the ACL cut-off at 1.4 and $0.7 \mathrm{~g}$ of hemoglobin per liter of plasma and further reached 10.7 and $22.7 \%$ at $14 \mathrm{~g}$ of hemoglobin per liter of plasma for urea level of 5 and $15.5 \mathrm{mmol} / \mathrm{L}$, respectively. Hemolysis led to a positive bias for creatinine which never exceeded the ACL cut-off up to $14 \mathrm{~g} / \mathrm{L}$ of hemoglobin concentration. Biases at this hemolysis level were 8 and $6 \%$ for creatinine concentrations of 46 and $142 \mu \mathrm{mol} / \mathrm{L}$, respectively.

To detect an effect of icterus interference, patients were classified into four groups according to icterus index (lower than $85.5 \mu \mathrm{mol} / \mathrm{L}$ versus more than $256.5 \mu \mathrm{mol} / \mathrm{L}$ for the control and the test group, respectively) and the level of analyte (Table 2). Icterus interference was found to be concentration-dependent with an effect observed only in patients with urea concentrations above $10 \mathrm{mmol} / \mathrm{L}$. Linear regression analysis between the bias and the icterus index in this sub-group was bias $=-0.041$ icterus index +0.575 , $r^{2}=0.30$. By contrast, the systematic bias between Cobas and ABL90 creatinine was affected by icterus in both groups. Linear regression analyses between the bias and the icterus index were bias $=0.28$ icterus index $-2.95, r^{2}=0.66$ and bias $=0.64$ icterus index $+0.40, r^{2}=0.47$ for the group of patients with creatinine levels below and above $100 \mu \mathrm{mol} / \mathrm{L}$, respectively. To further analyze the bias observed for creatinine, results were compared with those obtained by a UPLC/MS/MS method known to be interference-free (Figure 4). The comparative UPLC/MS/MS method showed no significant interference by bilirubin for ABL90 creatinine 

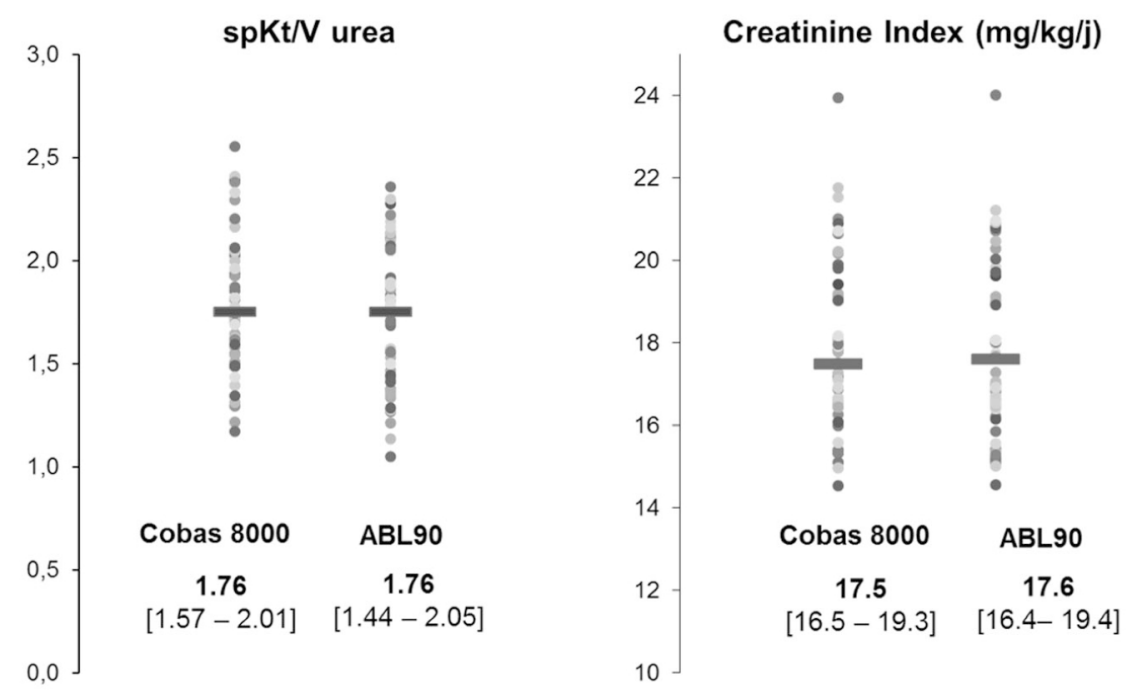

Figure 3. Assessment of dialysis adequacy using sp $K t / V$ and muscle mass using creatinine index: comparison between central lab and POCT.

Table 2. Icterus interference: median bias (ABL90 - cobas 8000) and the interquartile range in patients with icterus index below $85.5 \mu \mathrm{mol} / \mathrm{L}$ and above $256.5 \mu \mathrm{mol} / \mathrm{L}$.

\begin{tabular}{lllll}
\hline & \multicolumn{1}{c}{ Control group } & & \multicolumn{1}{c}{ Test group } \\
\cline { 2 - 3 } & Icterus index $<85.5 \mu \mathrm{mol} / \mathrm{L}$ & & Icterus index $>256.5 \mu \mathrm{mol} / \mathrm{L}$ & $p$ \\
\hline Urea $<10 \mathrm{mmol} / \mathrm{L}$ & $0.5[0.2-0.7] \mathrm{mmol} / \mathrm{L}$ & & $0.45[0.3-0.7] \mathrm{mmol} / \mathrm{L}$ & .783 \\
Urea $>10 \mathrm{mmol} / \mathrm{L}$ & $(n=30)$ & & $(n=30)$ & \\
& $0.6[-0.1$ to 1.2$] \mathrm{mmol} / \mathrm{L}$ & & $-0.6[-1.8$ to 0$] \mathrm{mmol} / \mathrm{L}$ & .004 \\
Creatinine $<100 \mu \mathrm{mol} / \mathrm{L}$ & $(n=29)$ & & $(n=21)$ & $<.001$ \\
& $-3[-4$ to 0$] \mu \mathrm{mol} / \mathrm{L}$ & $(n=25)$ & $5[1.3-8] \mu \mathrm{mol} / \mathrm{L}$ & $<.001$ \\
Creatinine $>100 \mu \mathrm{mol} / \mathrm{L}$ & $0[-6$ to 9$] \mu \mathrm{mol} / \mathrm{L}$ & & $(n=34)$ & \\
& $(n=33)$ & $(n=20)$ & & \\
\hline
\end{tabular}

(A)

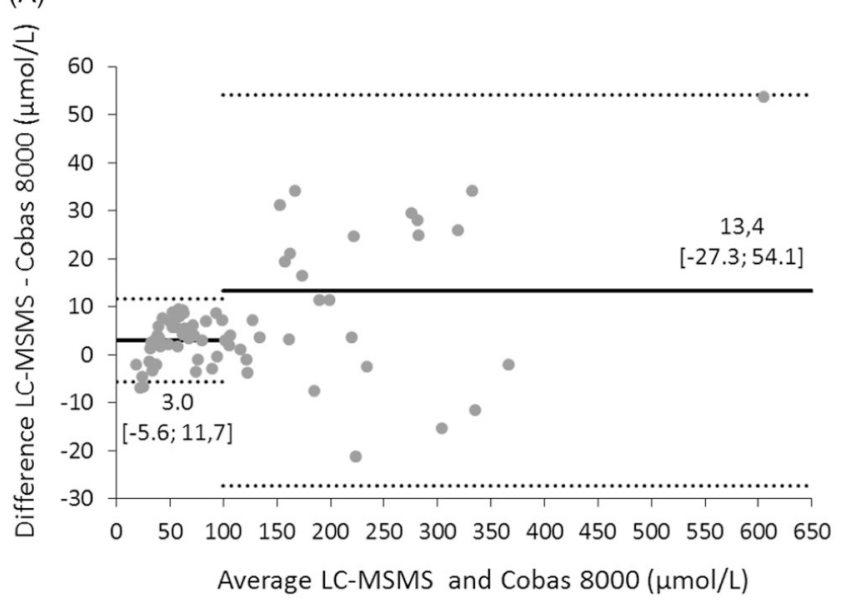

(B)

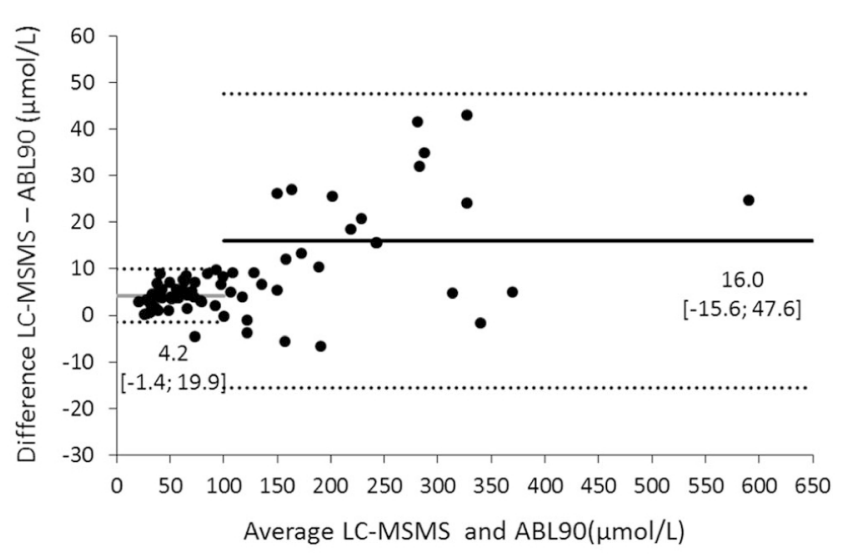

Figure 4. The Bland-Altman plot representation between enzymatic creatinine (A) on c701/Cobas 8000 and UPLC/MS/MS; (B) on ABL 90 Flex Plus analyzers and UPLC/MS/MS. The mean (solid horizontal line) and limits of agreement (dashed lines) of the bias ( $\mu \mathrm{mol} / \mathrm{L})$ were computed for patients with creatinine concentration $<100 \mu \mathrm{mol} / \mathrm{L}(n=44)$ and $>100 \mu \mathrm{mol} / \mathrm{L}(n=30)$.

with a constant mean bias of $4.2 \pm 2.9$ and $16 \pm 16.1 \mu \mathrm{mol} / \mathrm{L}$ in the group of patients with creatinine levels below and above $100 \mu \mathrm{mol} / \mathrm{L}$, respectively. By contrast, a significant bias was observed for Cobas creatinine proportional to bilirubin concentration (Figure 5). Linear regression analyses between the bias and the icterus index were bias $=-0.31$ icterus index $+6.9, r^{2}=0.62$ and bias $=-1.11$ icterus index $+27.8, r^{2}=0.45$ for the group of patients with creatinine levels below and above $100 \mu \mathrm{mol} / \mathrm{L}$, respectively.

\section{Discussion}

There are now increasing opportunities for measuring creatinine by POCT devices either on primarily blood gas analyzers like ABL90 or on 'non-blood gas' analyzers [13]. However, to the best of our knowledge, no analytical performance goals have been specifically published for POCT. It can be expected that analytical performances of POCT creatinine should meet the requirements regarding bias and 

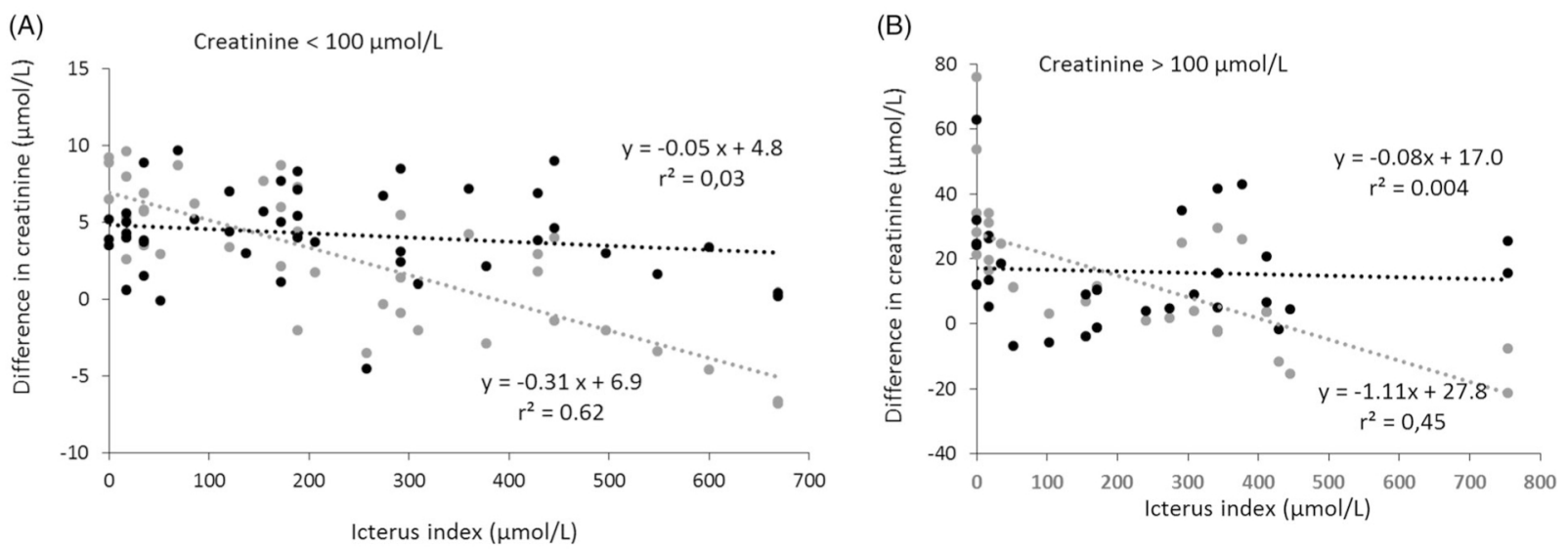

Figure 5. Difference in creatinine (ABL (black circle) or Cobas (grey circle) minus UPLC/MS/MS) versus icterus index in patients with creatinine concentration $<100 \mu \mathrm{mol} / \mathrm{L}(\mathrm{A}, n=44)$ and $>100 \mu \mathrm{mol} / \mathrm{L}(\mathrm{B}, n=30)$. Dotted line represents the best fit determined by regression analysis.

precision as for measurements implemented on biochemistry analyzer at the central lab. ABL90 enzymatic creatinine achieves desirable imprecision [24-26] based on biological variation (i.e. 2.25\%), comparable to that obtained on central lab biochemistry analyzer [27]. Urea reaches desirable imprecision (i.e. 6.95\%) at all levels and optimal specification (i.e. $3.48 \%$ ) except at the lower value of $1.1 \mathrm{mmol} / \mathrm{L}$. The dilution profiles obtained with the patient sample exhibited a high degree of linearity for creatinine and a slight deviation from linearity was observed for urea. Both assays presented good agreement with the central lab Roche assay, which is very important to ensure patient safety and optimize patient management in the point-of-care setting. Creatinine is the most important variable in all creatininebased equations to estimate GFR, and the relationship between creatinine and GFR is exponential. Therefore, bias which is the systematic error due to difference in calibration or imprecision in POC device measurements could strongly impact on eGFR results $[5,28]$. Bias has been improved by standardization of the measurement with the so-called IDMS traceability. The percent bias between ABL90 and Roche enzymatic creatinine in this study was $-1.4 \%$ (95\% $\mathrm{CI},-2.9 \%$ to $0.1 \%$ ) and the agreement at CKD diagnostic thresholds was $99 \%$. Our results confirmed the performances obtained by Salvagno et al. [29] on the same device who concluded that ABL90 enzymatic creatinine was as suitable as a conventional clinical chemistry enzymatic technique for routine and urgent diagnosis of kidney diseases. By contrast, a study comparing three handheld POC creatinine/eGFR analyzers available on the Belgian market reported that Nova StatSensor POC did not meet any of the analytical error criteria for creatinine (6\%) and gave more clinical major classification errors [30]. A recent Canadian study suggests that the limiting characteristic of the StatSensor may not be limited to bias, but also to imprecision with a CV ranging between $5.8 \%$ and $11.3 \%$ [31]. Analytical imprecision of routine methods and specially POCT systems is related to performances of the instruments but also to variability in day-to-day calibration, lot-to-lot variation. Long-term performance is a major problem and bias versus central lab is a critical issue that should be carefully monitored. Lot-to-lot variation has been reported as a major problem on the Abbotts i-STAT POC $[32,33]$. During the first year of implementation of the ABL90, we identified 32 combinations of batches of pack solutions and sensor cassettes. Median bias versus central lab, determined by periodic comparison, was 1.5 [IQR $0.7-3.2$ ] \% underlining the robustness of the results.

In a subgroup of $51 \mathrm{HD}$ patients, results for whole blood urea and creatinine well correlated with laboratory measurements in both pre-dialysis and post-dialysis samples. These results contrast with the negative bias $(-30 \%)$ against laboratory plasma creatinine observed using the Nova StatSensor creatinine meter in pre-dialysis patients that have been related to interferences arising from disease states [10]. Dialysis adequacy parameters could be derived from urea and creatinine. Urea kinetics and specially the $K t / V$ index, defined as the product of urea clearance $(K)$ and length of the treatment time $(t)$, in relation to the urea distribution volume, is an important determinant of dialysis performance and patient outcome [34]. In our study, the sp $K t / V$ was similar when calculated using central lab or POC method. Alternatively, creatinine index obtained by creatinine kinetic modeling, has been recognized as a surrogate biomarker of muscle mass in dialysis patients and has emerged as a significant predictors of protein nutritional status, all-cause and cardiovascular mortalities in HD patients [35,36]. Here again, creatinine index obtained by central lab method or by POCT system is totally identical, suggesting that beyond dialysis adequacy, muscle mass could be estimated using creatinine measurement by ABL90. Since the main advantage of POC devices is the quick result allowing a quick decision, the utility of a POC analyzer in dialysis unit may be questionable but the evaluation demonstrated that ABL90 is suitable for screening and monitoring kidney impairment throughout a wide measuring range, which would cover the vast majority of clinical samples [29]. Nevertheless, creatinine kinetic is a simple and a reliable tool for the assessment of protein nutritional status and muscle mass in dialysis patients that can be easily coupled to urea kinetics modeling [28]. In addition, it has been previously shown that ABL90 could be used to detect low levels of ionized calcium and thus could be suitable for the monitoring of citrate anticoagulation in renal replacement therapy [37]. 
High sample quality is essential to ensure the reliability of results in laboratory medicine and pre-analytical errors related to blood gas analysis could affect the results obtained by POCT. Since blood gas analysis is performed on whole blood, sample preparation is a key step, especially adequate sample mixing prior to analysis to obtain homogenous sample. In this study, urea and creatinine measurements were unaffected by hematocrit variation between 20 and $70 \%$. Special attention is needed with regard to hemolysis interference in whole blood analyses since the prevalence of hemolyzed samples referred for blood gas analysis has been reported as high as $4 \%$ [38] and hemolysis cannot be easily measured or visually checked. In agreement with Lippi results [39], hemolysis interfered with urea measurement but the difference never exceeded the desirable bias based on biological variation. Increased bilirubin (icterus) represents common sample abnormalities/circumstances found in neonates or during hepatic diseases with no possibility of a new sample without interference. Bilirubin could interfere via two mechanisms: spectrophotometric (light absorption) and chemical interference [40]. Urea was slightly impacted by bilirubin with no clinical consequence at this level. By contrast, a negative and dose-dependent interference by icterus was observed for Cobas creatinine but not ABL creatinine measurement. This interference has been previously described by Owen and Keevil [41] who found a significant negative bias between the Roche enzymatic method and LC-MS/MS method using anonymized icteric sera with creatinine concentrations less than $150 \mu \mathrm{mol} / \mathrm{L}$. It has been reported that bilirubin interferes negatively with enzymatic methods, and particularly with methods based on creatinine amidohydrolase (creatininase) $[42,43]$. This interference may be related to the competition between bilirubin and the assay substrate for the $\mathrm{H}_{2} \mathrm{O}_{2}$ produced in the adjacent reaction. As recently reported [44], the absence of interference seen with the ABL90 may be attributable to the detection principle of the final product.

This study acknowledges some limitations. Pre-analytical source of errors [45] such as inappropriate collection container, improper storage/handling/transport which have previously been shown to have a significant impact on the results were not evaluated.

\section{Conclusions}

ABL90 appears suitable for clinical use. The analytical imprecision meets the international recommendations with a moderate bias against the central lab method of $0.5 \mathrm{mmol} /$ $\mathrm{L}$ and $-0.9 \mu \mathrm{mol} / \mathrm{L}$ for urea and creatinine, respectively. Moreover, urea and creatinine measurement on ABL are not affected by the interferences from hemolysis and icterus, which are the most common interfering substances. In conclusion, rapid measurement of creatinine and urea using whole blood specimens on ABL90 appears as a fast and convenient method.

\section{Acknowledgements}

The authors acknowledge radiometer for providing quality control materials and reagents for this study. Radiometer has no role in direct ing the study or influencing the interpretation of the study results.

\section{Disclosure statement}

The authors have no conflict of interest to disclose.

\section{References}

[1] Oredsson S, Jonsson H, Rognes J, et al. A systematic review of triage-related interventions to improve patient flow in emergency departments. Scand J Trauma Resusc Emerg Med. 2011; 19:43.

[2] Jarvis PRE. Improving emergency department patient flow. Clin Exp Emerg Med. 2016;3(2):63-68.

[3] Bargnoux A-S, Beaufils O, Oguike M, et al. Point-of-care creatinine testing in patients receiving contrast-enhanced computed tomography scan. Clin Chim Acta. 2018;478:111-113.

[4] Stojkovic V, Delanaye P, Collard G, et al. Estimated glomerular filtration rate using a point of care measure of creatinine in patients with iohexol determinate GFR. Clin Chim Acta. 2019; 499:123-127.

[5] Snaith B, Harris MA, Shinkins B, et al. Point-of-care creatinine testing for kidney function measurement prior to contrastenhanced diagnostic imaging: evaluation of the performance of three systems for clinical utility. Clin Chem Lab Med. 2018; 56(8):1269-1276.

[6] McIntosh BW, Vasek J, Taylor M, et al. Accuracy of bedside point of care testing in critical emergency department patients. Am J Emerg Med. 2018;36(4):567-570.

[7] Love SA, Schulz K, Stack P, et al. Clinical evaluation of a new point-of-care system for chemistry panel testing. J Appl Lab Med. 2019;4(2):180-192.

[8] Goyder C, Tan PS, Verbakel J, et al. Impact of point-of-care panel tests in ambulatory care: a systematic review and metaanalysis. BMJ Open. 2020;10(2):e032132.

[9] Harris MA, Snaith B, Clarke R. Strategies for assessing renal function prior to outpatient contrast-enhanced CT: a UK survey. Br J Radiol. 2016;89(1067):20160077.

[10] Schnabl KL, Bagherpoor S, Diker P, et al. Evaluation of the analytical performance of the Nova StatSensor creatinine meter and reagent strip technology for whole blood testing. Clin Biochem. 2010;43(12):1026-1029.

[11] D'Orazio P, Conant J, Cervera J. Measurement of creatinine in whole blood samples supplemented to achieve increased creatinine concentrations. Clin Chem. 2008;54(2):451-452.

[12] Erickson KA, Wilding P. Evaluation of a novel point-of-care system, the i-STAT portable clinical analyzer. Clin Chem. 1993; 39(2):283-287.

[13] Shephard MD. Point-of-care testing and creatinine measurement. Clin Biochem Rev. 2011;32(2):109-114.

[14] Skurup A, Kristensen T, Wennecke G, et al. New creatinine sensor for point-of-care testing of creatinine meets the National Kidney Disease Education Program guidelines. Clin Chem Lab Med. 2008;46:3-8.

[15] User verification of precision and estimation of bias; approved guideline-third edition. CLSI document EP15-A3. Wayne (PA): Clinical and Laboratory Standards Institute; 2014.

[16] Evaluation of the linearity of quantitative measurement procedures: a statistical approach; approved guideline. CLSI document EP06-A. Wayne (PA): Clinical and Laboratory Standards Institute; 2003.

[17] Levey AS, Stevens LA, Schmid CH, et al. A new equation to estimate glomerular filtration rate. Ann Intern Med. 2009; 150(9):604-612. 
[18] Daugirdas JT. Simplified equations for monitoring Kt/V, PCRn, eKt/V, and ePCRn. Adv Ren Replace Ther. 1995;2(4):295-304.

[19] Terrier N, Jaussent I, Dupuy AM, et al. Creatinine index and transthyretin as additive predictors of mortality in haemodialysis patients. Nephrol Dial Transplant. 2008;23(1):345-353.

[20] Interference testing in clinical chemistry; approved guideline second edition. CLSI document EP07-A2. Wayne (PA): Clinical and Laboratory Standards Institute; 2005.

[21] Dupuy AM, Bargnoux AS, Kuster N, et al. Determination of hemolysis cut-offs for biochemical and immunochemical analytes according to their value. Clin Chem Lab Med. 2020;58(8): 1232-1241.

[22] ISO Standard 5725, accuracy (trueness and precision) of measurement methods and results. Geneva, Switzerland: International Organization for Standardization; 1994.

[23] Lippi G, Cadamuro J, von Meyer A, et al. Practical recommendations for managing hemolyzed samples in clinical chemistry testing. Clin Chem Lab Med. 2018;56(5):718-727.

[24] Aarsand AK, Fernandez-Calle P, Webster C, et al. The EFLM biological variation database; 2019. [Internet]. Available from: https://biologicalvariation.eu/

[25] Sandberg S, Fraser CG, Horvath AR, et al. Defining analytical performance specifications: consensus statement from the 1st strategic conference of the European Federation of Clinical Chemistry and Laboratory Medicine. Clin Chem Lab Med. 2015;53(6):833-835.

[26] Fraser CG. General strategies to set quality specifications for reliability performance characteristics. Scand J Clin Lab Invest. 1999;59(7):487-490.

[27] Piéroni L, Delanaye P, Boutten A, et al. A multicentric evaluation of IDMS-traceable creatinine enzymatic assays. Clin Chim Acta. 2011;412(23-24):2070-2075.

[28] Bargnoux AS, Kuster N, Cavalier E, et al. Serum creatinine: advantages and pitfalls. J Lab Precis Med. 2018;3:71.

[29] Salvagno GL, Pucci M, Demonte D, et al. Analytical evaluation of radiometer ABL90 FLEX PLUS enzymatic creatinine assay. J Lab Precis Med. 2019;4:26.

[30] van der Heijden C, Roosens L, Cluckers H, et al. Analytical and clinical performance of three hand-held point-of-care creatinine analyzers for renal function measurements prior to contrastenhanced imaging. Clin Chim Acta. 2019;497:13-19.

[31] Nataatmadja M, Fung AWS, Jacobson B, et al. Performance of StatSensor point-of-care device for measuring creatinine in patients with chronic kidney disease and postkidney transplantation. Can J Kidney Health Dis. 2020;7:2054358120970716.

[32] Papadea C, Foster J, Grant S, et al. Evaluation of the i-STAT portable clinical analyzer for point-of-care blood testing in the intensive care units of a university children's hospital. Ann Clin Lab Sci. 2002;32:231-243.

[33] Bahar B, DeChristopher PJ, Holmes EW, et al. Investigation of falsely decreased creatinine results observed from the Abbott ISTAT point-of-care device in use for testing specimens from ambulatory oncology patients. Point Care. 2016;15(2):72-77.

[34] Couchoud C, Jager KJ, Tomson C, et al. Assessment of urea removal in haemodialysis and the impact of the European Best Practice Guidelines. Nephrol Dial Transplant. 2009;24(4): $1267-1274$

[35] Huang CY, Lee SY, Yang CW, et al. A simpler creatinine index can predict long-term survival in Chinese hemodialysis patients. PLoS One. 2016;11(10):e0165164.

[36] Canaud B, Granger Vallée A, Molinari N, et al. Creatinine index as a surrogate of lean body mass derived from urea Kt/V, pre-dialysis serum levels and anthropometric characteristics of haemodialysis patients. PLoS One. 2014;9(3):e93286.

[37] Larcher R, Kuster N, Bargnoux AS, et al. Discrepant post-filter ionized calcium concentrations by 2 common gas analyzers in continuous renal replacement therapy using regional citrate anticoagulation: another piece of the puzzle. Kidney Int. 2021; 99(1):268-269.

[38] Lippi G, Fontana R, Avanzini P, et al. Influence of spurious hemolysis on blood gas analysis. Clin Chem Lab Med. 2013;51: 1651-1654.

[39] Lippi G, Salvagno GL, Montagnana M, et al. Influence of hemolysis on routine clinical chemistry testing. Clin Chem Lab Med. 2006;44:311-316.

[40] Nicolay A, Lorec AM, Gomez G, et al. Icteric human samples: icterus index and method of estimating an interference-free value for 16 biochemical analyses. J Clin Lab Anal. 2018;32(2): e22229.

[41] Owen LJ, Keevil BG. Does bilirubin cause interference in Roche creatinine methods? Clin Chem. 2007;53(2):370-371.

[42] Cobbaert CM, Baadenhuijsen H, Weykamp CW. Prime time for enzymatic creatinine methods in pediatrics. Clin Chem. 2009;55(3):549-558.

[43] Greenberg N, Roberts WL, Bachmann LM, et al. Specificity characteristics of 7 commercial creatinine measurement procedures by enzymatic and Jaffe method principles. Clin Chem. 2012;58(2):391-401.

[44] Roelofsen-de Beer RJAC, van Zelst BD, Vroling AB, et al. When results matter: reliable creatinine concentrations in hyperbilirubinemia patients. Clin Chem Lab Med. 2019;57(5): 659-667.

[45] Baird G. Preanalytical considerations in blood gas analysis. Biochem Med (Zagreb). 2013;23(1):19-27. 